\title{
Till tolkningen av runstenen vid Vändle (Vs 4).
}

\section{Henrik Williams}

Vid Norrgården, Vändle, i Dingtuna socken, halvannan mil östsydöst om Västerås, står idag toppartiet av en runsten från sen vikingatid lutat mot ett träd (fig. 1).

Fragmentet utgör övre delen av ett monument och påträffades ungefär 1895 enligt Sven B. F. Jansson som också återger vad Erik Brate i en opublicerad rapport skrev om fyndet: "Runstenen, som blott utgör en del af en sådan, hittades vid afplanandet efter rifningen af en mycket gammal byggnad, som stod nedanför Vendle Norrgård, nedanför höjden, på hvilken denna ligger, mellan dess ladugård och landsvägen; stenen hade legat i grundvalen till denna byggnad.”1ㅡㄹ tog således 70 år innan Vs 4 publicerades, även om dess inskrift kort nämndes 1958 av Arndt Ruprecht i en fotnot (se nedan). Förutom ett kort omnämnande av Per Stille i samband med en ristardiskussion ${ }^{2}$ har inskriften såvitt jag vet i den vetenskapliga litteraturen bara berörts av Patrik Larsson som behandlar dess bruk av R-runan. ${ }^{3}$ Själva tolkningen av runtexten har inte fått någon uppmärksamhet. Det kan vara dags att intressera sig för

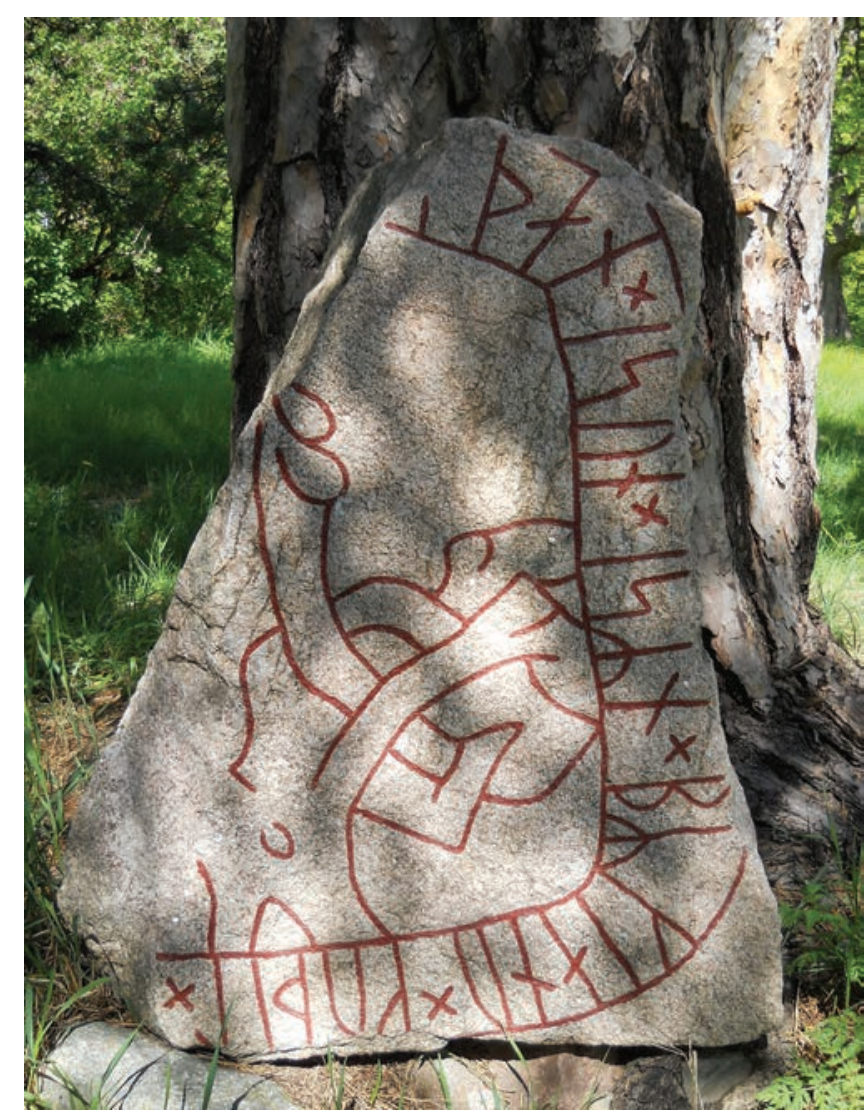

Fig. 1. Runstenen Vs 4 vid Vändle, Norrgården i Dingtuna sn, Tuhundra hd, Västmanland. Stenen står vriden 90 grader till höger jämfört med hur den har varit rest men visas här rättvänd. Foto av Henrik Williams 2011. denna, enligt min mening underskattade runsten.

\footnotetext{
1 I SRI 13, s. 15.

2 Stille 1999, s. 136 not 39.

3 Larsson 2002.
} 
Jansson (a. st.) ger följande läsning, runsvenska tolkning och översättning till modern svenska: ${ }^{4}$

... - pan $\times$ isun $\times$ isRn $\times$ brkianu $\times$ kupil $\times \ldots$

... [go]ðan, sun sinn. Biðia nu Guð hial[pa] ... (?)

»..., sin son. De bedja nu Gud hjälpa ... (?)»

Det råder ingen tvekan om hur runorna ska läsas (jfr nedan), även om de används på ett delvis okonventionellt sätt med ett slags vokalisk upptakt framför initialt /s/ och med R-runan representerande vokal. Båda dessa egenheter är dock kända från andra runstenar och utgör dessutom ledtrådar till vem som har ristat runtexten (en fråga till vilken jag tänker återkomma i ett annat sammanhang). Denne ristare har enligt Jansson varit den samme som utfört inskriften på en närbelägen runsten vid Tumbo kyrka i Södermanland, rakt söder om Vändle. Han skriver: ”Vs 4 visar överensstämmelser med den ovan nämnda, likaledes fragmentariska Tumbostenen (Sö 82). Det är möjligt, att de båda stenarna har ristats av samme man, även om ristningen på Tumbostenen förfaller vara av något högre kvalitet.”5 Jansson nämner inte ornamentiken som ett skäl för att sammanställa dessa runstenar, men det är helt uppenbart att det mycket märkliga rundjurshuvud som återstår av figurframställningen på Vs 4 är detsamma som återfinns på Sö 82 (fig. 2). Mellan de båda ristningarna är avståndet, som Jansson påpekar, bara halvannan mil. ${ }^{6}$ Inskriften på Sö 82 var vid Erik Brates publicering delvis dold av en tröskel. ${ }^{7}$ Den togs dock fram 1930 och dess lydelse kunde fyllas ut av Elias Wessén. ${ }^{8}$ Utifrån Brates läsning och översättning (någon transkription ges ej) samt Wesséns komplettering därav kan därmed inskriften återges på följande sätt (de runda parenteserna markerar osäkra läsningar och används i stället för de kursiverade tecken som brukas av Brate; hakparenteserna markerar läsning efter äldre teckning):

\section{[+] ui--(a)n [ $\times($ b)a-]iR $\times$ (i)prn + RftRh $\times$ fraitRn $\times$ brupur $\times$}

is $(\mathrm{R}) \mathrm{n} \times$ pupr $\times$ kRkum $(\times \mathrm{b})[\mathrm{u}] \mathrm{I}[\mathrm{R} \times$ iuk $\times](\mathrm{u})[\ln \times]$

Visten reste stenen efter - sin broder, död i Grekland. Tule högg runorna.

Den karakteristiska användningen av R-runan för vokal och skrivningen isRn skulle kunna föranleda ett tvärsäkert omdöme att monumenten utförts av samma ristare, men det finns anledning att vara försiktig. Den kvalitetsskillnad i ristningsteknik som Jansson uppmärksammade visar sig vara giltig också för ornamentiken. Nosen på rundjuret är trunkerad på Sö 82 men på Vs 4 är båda käkarna helt avhuggna och hornkronans uppbyggnad annorlunda, möjligen missuppfattad. Detta aktualiserar ett förslag av Anne-Sofie Gräslund att runstenars formgivning kunde imiteras av andra ristare, ibland

4 Jansson (i SRI 13, s. 16) anser att Vs 4 är en "av allt att döma jämförelsevis ung runinskrift (1100-talet)”, vilket Larsson (2002, s. 153) med goda skäl betvivlar.

5 I SRI 13, s. 16.

6 I SRI 13, s. 15.

7 I SRI 3, s. 60.

8 I SRI 3, s. 383. 
Fig. 2. Runstenen Sö 82 vid Tumbo kyrka, Tuhundra hd, Södermanland. Foto av Jonas Nordby 2007.

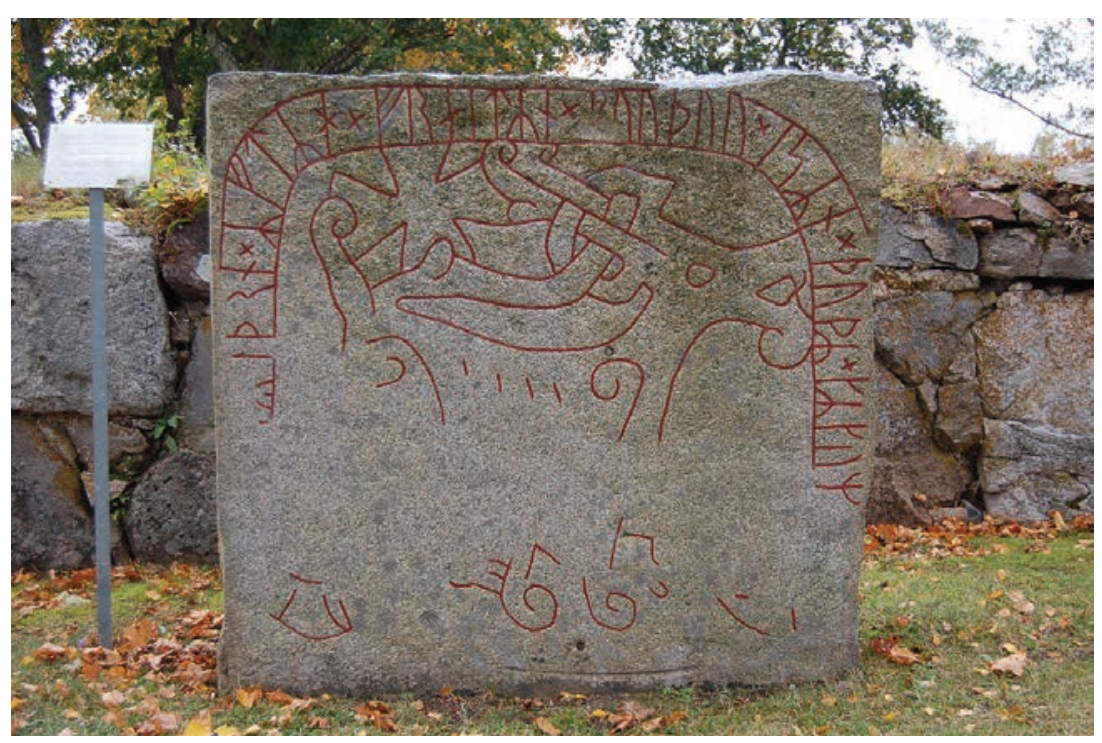

med mindre lyckat resultat. ${ }^{9}$ Jag vill dock ändå påstå att run- och språkformer, typ av skiljetecken och ortografi alla talar för att vi har att göra med samme ristare för Vs 4 och Sö 82 och att denne har stått för ytterligare två eller flera stenmonument. Det är dock inte i detta sammanhang av avgörande betydelse; denna lilla uppsats skall begränsa sig till tolkningen av Vs 4.

Det som i första hand förvånar med Janssons tolkning är uppfattningen att bakom bRkianu skulle dölja sig ordet biðia 'bedja'. Det kan tyckas vara ett mysterium hur någon kan komma fram till att läsa en k-runa som representerande /ð/. Janssons resonemang lyder: »Man tvingas att räkna med en felristning, vilket med hänsyn till att ristaren tydligen är oövad är försvarligt. Det är sålunda möjligt, att han har råkat rista k i st. f. p i runföljden brkianu.» ${ }^{10}$ Av det som följer framgår att förslaget har varit i säck innan det kom i påse eftersom Ruprecht försökte tolka inskriften på detta sätt. ${ }^{11}$ Han har vid sin läsning uppfattat k-runans bistav som en naturlig skåra men tycker sig se en vittrad båge som skulle utgöra p-runans båge, annars ger runföljden enligt honom ingen mening. Jansson skriver dock att "inskriften är i stort sett tydlig” och han läser som vi har sett utan reservation ett $\mathbf{k}$ på det aktuella stället, ändå följer han märkligt nog Ruprechts tolkningsförslag. ${ }^{12}$ Men Jansson har säkerligen också påverkats av inskriften på den en gång närbelägna men nu försvunna runstenen Vs 3 Kävlinge (Bysingsberg) som löd:

Ingirun let roeisa stcein penna ceftir ... [Ing]ivald o[k] ..., drcengia goða. Ok moelti pat [ok] baðи Guð hialpa salu poeiRa. 'Ingerun lät resa denna sten efter (sina söner) Ingevald och ..., goda ”drängar”. Och sade det (och) bådo Gud hjälpa deras själar.'

9 Gräslund 2011, s. 152 f.

10 I SRI 13, s. 16.

11 Ruprecht 1958, s. 105 not 57).

12 I SRI 13, s. 15. 
Helst skulle man vilja se ackusativformen av den döde sonens namn i brkianu, men det har inte lyckats mig att föreslå något sådant. Inte heller kan jag se att slutet av ett dylikt skulle återfinnas i runföljden - pan. Jansson menar troligen med rätta att:

Runföljden 1-4 - pan torde kunna suppleras kopan, goðan (ack.). I så fall vågar man kanske räkna med att adjektivet har föregåtts av substantivet drceng (ack.); jfr drcengia goða på Vs 3. Det bör emellertid framhållas, att de appositionella bestämningarna till den dödes namn här komma i annan följd än den vanliga. Man skulle ha väntat formuleringen $N$. N., sun sinn, dræeng goðan, icke drceng goðan, sun sinn. ${ }^{13}$

Jansson hänvisar till Elias Wesséns historiska syntax där regeln mycket riktigt är att apposition följer sitt huvudord, men som Wessén också påpekar kan appositionen också stå före ett namn. ${ }^{14}$ Något sådant är det dock inte tal om på Vs 4 och dess runtext är unik så till vida att den efterställda appositionen där gäller om en son. Det finns däremot exempel på typen "efter NN, epitet apposition, relation sin” (med vissa variationer), vad gäller fader (Vg 74(?), Vg NOR1997;27), make (Vg 154) och troligen moder (G 114) samt någon annans brorson (Vg 158). Vg 74 kan trots sin skadade status ges som ett särskilt tydligt exempel:

Aguti(?) roeisti stcein pannsi oeftiR Asgaut, pegn harða go[ðan, fað]ur(?) sinn

'Agute(?) reste denna sten efter Åsgöt, sin fader, en mycket god tägn.'

Av någon anledning verkar denna konstruktion framförallt förekomma i Västergötland, även om det inte utesluter att den också har brukats i Västmanland. Att ordet dräng skulle ha nämnts på Vs 4 är dock bara en spekulation men säkert är att runtexten måste ha varit formulerad på ett unikt sätt.

Avgörande är i första hand hur man tolkar belägget brkia. Om man läser som det står finns följande teoretiska ljudunderlag: $b / p+i / e / c e(+n)+k(k) / g(g)+i a$. Möjligt är att vi här har att göra med ett personnamn, även om det enda alternativet i belagt fornspråkligt material i så fall verkar vara binamnet Bikki konstruerat utifrån genitivformen (Ketils) Bikkia, belagd på en namnbärare $1353 .{ }^{15}$ Som huvudnamn har detta namn dock den oblika formen Bikka. ${ }^{16}$ Antingen skall diplomformen i stället ses som ett belägg på ett binamn Bikkia, ${ }^{17}$ som då oregelmässigt står oböjt, eller måste man anta att Bikki har kunnat böjas både som an-stam och jan-stam. Textmönstret "(efter) epitet, relation sin, NN" saknar dock helt paralleller.

Av de tolkningsalternativ som återstår framstår bara ett som rimligt, det runsvenska räkneordet breggia 'bådas', genitiv av baðiR, ${ }^{18}$ och jag utgår fortsättningsvis från detta alternativ utan att det därför med nödvändighet måste vara det rätta. I runnordiska in-

13 I SRI 13, s. 16.

14 Wessén 1965, § 68, s. 100.

15 Se Lind 1920-21, sp. 23.

16 Lind 1905-15, sp. 138.

17 Jfr Lind 1920-21, sp. 23.

18 Jfr Noreen 1904, § 481. 
skrifter är bæeggia för övrigt belagt bara två gånger, på Ög 239 som avslutas Guð hialpi salu pceira bceggia. 'Gud må hjälpa båda deras själ' och DR 389 Krist hcelgi hialpi siolu pera brøpra bœeggia. 'Den helige Kristus må hjälpa båda deras bröders själ'.

Formen breggia förutsätter i fall som dessa förekomsten av en annan genitivisk bestämning, vilken vi också återfinner i de nyss nämnda inskrifternas pceira/pera och på Vs 4 i sinn. Man kan därför pröva att avsluta meningen efter bceggia och översätta första delen av inskriften som att två föräldrar har åstadkommit en runsten efter sin gemensamme son, antingen han nu "bara" ges epitetet god eller såsom Jansson framkastar beskrivs som en god "dräng”. Tolkningen skulle då bli ... [go]ðan, sun sinn bæeggia, fritt översatt 'en god son till dem bägge'. Det är svårt att ge en bokstavlig nusvensk version som inte ger svag form till adjektivet god och hanterar både sin son och bägges. Om man gör avkall på det första kravet kanske '(efter NN,) bägges sin gode son' kommer närmast. Det är enligt min mening sannolikt att den ytterligare apposition som utgörs av bæeggia bidragit till den ovanliga syntaxen: förbindelsen sun sinn bæeggia är ett tungt satsled som av rytmiska skäl har lagts sist i meningen.

Appositionen bæeggia används i de ovan nämnda exemplen från Ög 239 och DR 389 rimligen för att understryka att det är själarna tillhörande båda avlidna som det bedes för. I översättning skulle man kanske helst tala om 'deras själar'. Av någon anledning vill dock inte vikingatida skribenter använda sig av ordet $s(i) a l(a)$ i pluralis, något som inte gäller medeltida runristare, t.ex. i 1300-talsinskriften G 33 som avslutas Biðin fyrir pceira sialum. 'Bedjen för deras själar!' I fallet Vs 4 måste det dock finnas någon annan förklaring till användningen av bæeggia eftersom sun sinn ensamt skulle ha visat att sonen var barn till båda föräldrarna. Jag förmodar därför att det förekom andra söner eller möjligen döttrar i familjen som inte hade gemensamma föräldrar med den på Vs 4 omnämnde sonen. Kanske det till och med restes en sten över någon av dem. Att motsatsen kunde förekomma, det vill säga att en sten restes över en man som inte var son till faderns hustru är helt klart, se till exempel U 310 där Estrid kungör att hon har låtit göra en bro efter sin make Ingvar och efter Ragnvald, hans(!) son (se också DR 317), eller till moderns make som Sö 37 vilken Holmsten och Vigun har låtit resa efter hennes(!) son, Ingefast. Till den senare inskriften bildar alltså Vs 4 en parallell, fast så att säga tvärtom.

Om Vs 4 har varit stor kan man till och med tänka sig att dess text varit formulerad något $\mathrm{i}$ stil med att ' $\mathrm{X}$ och $\mathrm{Y}$ reste sten efter $\mathrm{Z}$, son till $\mathrm{X}$, och efter $\mathrm{A}$., bägges sin gode son.' Men det är en helt och hållet hypotetisk tanke och saknar veterligen riktiga paralleller. Det kan däremot vara värt att erinra om inskriften på Sö 101: Sigriðr gærði bro pasi, moðir Alriks, dottin Orms, for salu Holmgceins, faður SigrøðaR, boanda sins 'Sigrid, moder till Alrik och dotter till Orm, gjorde denna bro för Holgers, sin makes (fader till Sigröd), själ.’ Som Magnus Källström har påpekat nämns här två särkullsbarn, Sigrids egen son Alrik och hennes mans son Sigröd, bägge födda under makarnas tidigare äktenskap med andra kontrahenter. ${ }^{19}$ Ett påpekande om att någon var barn till bägge stenresarna är alltså inte orimligt att tänka sig.

19 Källström 2010, s. 133 f. med litt. 
Vad som också bör hållas i minnet är att minst sex ord rimligen bör har föregått det som nu återstår av inskriftens inledning: båda föräldrarnas namn förenade med en konjunktion, ett ristarverb, en monumentbeteckning samt sonens namn (om det inte döljs i ...-pan; inget namn ändande sålunda verkar dock finnas), omfattande åtminstone ett trettiotal runor och sannolikt fler. Texten bör därför ha löpt längs stenens långsida ytterligare 1,5 meter och minnesmärket med rotända därmed varit över två meter. Jansson skriver också: "Ursprungligen har stenen tydligen varit ganska stor."20 Vad viktigare är att denna observation får konsekvenser också för inskriftens avslutning som måste ha innehållit förhållandevis mycket text, ytterligare säkert minst fem ord. Vi måste därför räkna med en total omfattning på minst 17, troligen uppåt 20 ord, vilket skulle göra runtexten till en överstigande medellängden på högst 14 ord. ${ }^{21}$ Men det återstår att utreda hur avslutningen har lytt, åtminstone hur den har inletts.

Jag har avsiktligt avstått från att ta större hänsyn till ett faktum som flera läsare vid det här laget kanske har sett som ett förbiseende, nämligen att runföljden brkia inte alls lyder så utan alltså brkianu. Att de två sista runorna måste tolkas som nu konstaterade redan Ruprecht (1958:105 not 57). Man bör hålla i åtanke att ristaren av Vs 4 inte konsekvent använder sig av interpunktion för att markera ordgränser. I den korta text som återstår saknas skiljetecken också i runföljden kupil som enligt de två tidigare uttolkarna re-presenterar Guð hial[pi], en bedömning jag ser mig nödgad att stödja i brist på bättre alternativ. (Dessutom används i kupil× interpunktion mitt i ett ord, möjligen markerande stavelsegräns.) Skiljetecken saknas också mellan de två avslutande orden på den av samme ristare huggna U 519: isi kup Se Guð. 'Må Gud se (honom). '22 Ett memento, möjligen inte av avgörande vikt, är att Ruprecht och Jansson för sitt $n u$ till samma mening som biðia, medan jag räknar med att de ingår i två olika meningar, trots att de inte åtskiljs på något sätt. Det är dock ovanligt att skiljetecken saknas mellan meningar om inte i stället ornamentala linjer eller byte av slinga signalerar ett syntaktiskt brott. Ett säkert exempel återfinns dock på U 951 där B-sidan lyder: at oupmunt kiRimr : skalt hiu ... at Auðmund. Grims Skald hio '... efter Ödmund. Grim skald högg. ${ }^{23}$ Grim tillhör de mindre framstående runristarna, liksom upphovsmannen bakom Vs 4, vilket möjligen är en faktor att beakta.

Det återstår då att diskutera den avslutande satsen på Vs 4, eller åtminstone vad som är kvar av den. Som har framgått ovan räknar jag med att det går en meningsgräns mellan breggia och nu. Därmed står vi med satsinledningen $N u$ Guð hial[pi] ... 'Nu må Gud hjälpa ...'. Hur denna mening har avslutats är ovisst, men som jag har visat ovan finns det anledning att räkna med ett flertal ord, alltså inte bara 'hans/NNs ande/själ' utan ytterligare några. Den förmodade formen $\mathbf{i l} \times<\mathbf{b i}>$ för hialpi behöver också en kommentar. Förutom förekomsten av ett skiljetecken i stavelsegräns är ortografin inte oväntad; obruten form har funnits på den närbelägna Vs 5 [helb]i, skrivningen ilbi är belagd även

20 I SRI 13, s. 15.

21 Jfr Williams 2013, s. 66.

22 Se Williams 2008, s. 9.

23 Se SRI 9, s. 69. 
på U 160, U 341 och U 696, och $h$-lös form av hialpi är att förvänta sig från ristaren av Vs 4: på sina andra två monument skriver han iuk hiogg 'högg'.

Västmanland utmärker sig inte för några utförliga runstensböner - längst är den på Vs 9 Guð hialpi hans and ok selu 'Må Gud hjälpa hans ande och själ' -, men det kanske inte är så märkligt med tanke på landskapets relativt få kända resta stenar med runristning, högst 25. Från det närbelägna Uppland kan dock hämtas ett antal längre böneformuleringar som hypotetiskt vore tänkbara på Vs 4: Guð drottinn hialpi anda hans boetr poen hann hoefir til goert 'Må Herren Gud hjälpa hans ande bättre än han (själv) har medverkat till' (U 759), Guð hialpi hans and ok Guðs moðiR 'Må Gud och Guds moder hjälpa hans ande' (U 860), Guð hialpi sal hans, boanda Ingur 'Må Gud hjälpa hans, Ingas makes, själ' (U 873) samt Guð hialpi and hans ok Haralds 'Må Gud hjälpa hans och Haralds ande’ (U 769).

Särskilt den sistnämnda bönen är av intresse eftersom inskriftens första del lyder Skarði rceisti stcein penna aftik Otrygg, sun sinn 'Skårde reste denna sten efter Otrygg, sin son'. Den veterligen unikt formulerade bönen handlar alltså inte bara om den på U 769 ihågkomne Otrygg utan också om den i övrigt okände Harald. Sven B. F. Jansson skriver: ”I vilket förhållande denne Haraldr har stått till Skarði framgår ej av inskriften. Det är icke uteslutet, att Harald kan ha varit en tidigare död son, vars minne fadern har velat hedra på stenen efter Otrygg.” ${ }^{24}$ Det är högst troligt, men enligt min mening är det i så fall sannolikt att U 769 utgör en del av ett parmonument där den andra, nu försvunna runstenen, har rests till minne av Harald och det där framgått vilken relation han hade till Skårde.

Det är dock att märka att ristaren av Vs 4 inte tillhör dem som använder långa böner, precis tvärtom, åtminstone om man ska döma av bönen på den av honom signerade U 519; den lyder som ovan nämnts bara Se Guð. Visst är det möjligt att bönen på Vs 4 var längre, men det finns en bättre lösning. I de andra två av samme ristare säkert utförda inskrifterna återfinns nämligen signaturer: på Sö 82 pulk hiogg run[aR](?) 'pulR högg runorna(?)’ som avslutande mening efter nekrologen, på U 519 pulir hiogg runar pessi 'pulir högg dessa runor' inskjutet före bönen. Det är därför möjligt men naturligtvis obevisbart att inskriften på Vs 4 har avslutats med en kort bön följd av en ristarsignatur; om vi räknar med fem ord förslagsvis 'Nu må Gud hjälpa [NNs/hans ande/själ. pul(i)R högg runorna.]'

Adverbet nu används i ett antal runnordiska monumentinskrifter, ibland i just böner: Guð hicelpi sal hennar vel nu 'Må Gud hjälpa hennes själ väl nu' (U 808) och Guð hialpi and hans nu 'Må Gud hjälpa hans ande nu' (U 818). Placeringen av nu kan som Wessén påpekar skifta, enligt honom för att undvika ställning omedelbart efter ett predikatverb. ${ }^{25}$ Ibland kommer adverbet först i satsen som på DR 296 Nu skal standa sten a biargi 'Nu skall stenen stå på berget' samt även i böner som på U 947 Nu es sal sagat sva: hialpi Guð 'Nu är det för själen sagt så: må Gud hjälpa (den).' Den kanske bästa parallellen till bönen på Vs 4 finns på U 341 som i sin helhet lyder Ingialdr(?) let ræisa stcin pennsa

24 I SRI 8, s. 340.

25 Wessén 1965, s. 209. 
aeftiR Kalf, faður sinn, ok aeftiR Igu [l], broður sinn, ok aftiR Ragnvi, møy ${ }^{26}$ sina. Nu hialpi Guð salu poeiRa ok Guðs moðir. Detta kan översättas 'Ingjald lät resa denna sten efter sin fader Kalv och efter sin broder Igel och efter sin dotter Ragnvi. Nu må Gud och Guds moder hjälpa deras själar.' Ordföljden är den förväntade efter satsinledande adverb med finitet på andra plats och subjektet närmast därefter; ${ }^{27}$ "Rak ordföljd är mycket ovanlig i en mening, som inledes med ett tidsadverb”. ${ }^{28}$ Det förekommer dock alltså men är icke desto mindre en vägande invändning mot min ovan föreslagna tolkning. Jag förmodar att orsaken till den i så fall oväntade ordföjden kan vara att subjektet föregår predikatet på Vs 4 för att ordet Guð på detta sätt framhävs.

Runstenen vid Vändle har en gång varit ett mycket mer imponerande monument än vad dess i dag fragmentariska skick kanske utvisar. Oavsett hur man förstår dess text verkar den ha varit formulerad på ett unikt sätt, men sannolikt inte så avvikande att den bör avfärdas som otolkbar. Unik blir också ordföljden i den av mig föreslagna tydningen av inskriftens nu avslutande del. Möjligen finns det andra och bättre tolkningsalternativ. Denna uppsats gör inte anspråk på att vara sista ordet i frågan, snarast första repliken i ett samtal om en märklig runsten som förtjänar mer uppmärksamhet.

Efter utredningen ovan och med vederbörliga reservationer vill jag föreslå möjligheten av att den kvarvarande texten på Vs 4 skall tolkas och översättas på följande sätt:

[go]ðan(?), sun sinn breggia. Nu Guð hial[pi] ...

'... bägges sin gode son. Nu må Gud hjälpa ...'

Jag riktar ett varmt tack till Magnus Källström, Stockholm, för värdefulla kommentarer till denna uppsats.

\section{Litteratur och förkortningar}

Danmarks runeindskrifter (1941). Ved Lis Jacobsen \& Erik Moltke under medvirkning af Anders Bæksted \& Karl Martin Nielsen. Text. 1941. København.

DR = Runristning i Danmarks runeindskrifter.

$\mathrm{G}=$ Runristning i SRI 11-12.

Gräslund, Anne-Sofie (2011), 'Similarities or Differences? Rune Stones as a Starting Point for Some Reflections on Viking Age Identity', Viking Settlement and Viking Society: Papers from the Proceedings of the Sixteenth Viking Congress, Reykjavik and Reykholt, 16-23 August, 2009. Ed. Svavar Sigmundsson. (Fylgirit Árbókar Hins íslenzka fornleifafélags 2011.) Reykjavík. S. 147-61.

Gustavson, Helmer (1997), 'Verksamheten vid Runverket i Stockholm', Nytt om runer 12, s. 24-31.

26 För tolkningen av detta ord se Isaksson 1994, s. 36.

27 Wessén 1965, s. 208.

28 Wessén 1965, s. 209 anm. 1. 
Isaksson, Bo (1994), Värdet av runuppteckningar från 1500- och 1600-talen. C-uppsats, Institutionen för nordiska språk, Stockholms universitet. Duplikat.

Källström, Magnus (2010), 'Hårds dotter och Gillögs son', Namn - en spegel av samhället förr och nu. Red. Staffan Nyström. Stockholm. S. 115-35.

Larsson, Patrik (2002), Yrrunan. Användning och ljudvärde i nordiska runinskrifter. (Runrön 17.) Uppsala.

Lind, E. H. (1905-15), Norsk-isländska dopnamn ock fingerade namn från medeltiden. Samlade ock utgivna. Uppsala-Leipzig.

- (1920-21), Norsk-isländska personbinamn från medeltiden. Samlade ock utgivna med förklaringar. Uppsala.

Noreen, Adolf (1904), Altschwedische grammatik mit einschluss des altgutnischen.

(Sammlung kurzer germanischen dialekte 8. Altnordische grammatik 2.) Halle.

Ruprecht, Arndt (1958), Die ausgehende Wikingerzeit im Lichte der Runeninschriften.

(Palaestra 224.) Göttingen.

SRI = Sveriges runinskrifter. Utg. av Kungl. Vitterhets Historie och Antikvitets Akademien 1-. 1900 ff. Stockholm.

Stille, Per (19999, Runstenar och runristare i det vikingatida Fjädrundaland: En studie i attribuering. (Runrön 13.) Uppsala.

Sö = Runristning i SRI 3.

U = Runristning i SRI 6-9.

Wessén, Elias (1965), Svensk språkhistoria 3: Grundlinjer till en historisk syntax. 2 uppl.

(Nordiskt kursbibliotek.) Stockholm-Göteborg-Uppsala.

Williams, Henrik (2008), Runestone Inscriptions and Queer Theory. (E. C. Quiggin

Memorial Lectures 10.) Cambridge.

- (2013), 'Runstenarnas sociala dimension, Futhark 4, s. 61-76.

$\mathrm{Vg}=$ Runristning i SRI 5.

Vg NOR1997;27 = Runristning från Hols kyrka i Västergötland publicerad i Gustavson (1997):27.

Vs = Runristning i SRI 13.

Ög = Runristning i SRI 2. 